\title{
COVID-19 pneumonia: microvascular disease revealed on pulmonary dual-energy computed tomography angiography
}

\author{
Franck Grillet $^{1 \#}$, Andreas Busse-Coté ${ }^{1 \#}$, Paul Calame ${ }^{1}$, Julien Behr $^{1}$, Eric Delabrousse ${ }^{1,2}$, Sébastien Aubry ${ }^{1,2}$ \\ ${ }^{1}$ Department of Radiology, Centre Hospitalier Universitaire de Besancon, Besancon, France; ${ }^{2}$ Nanomedecine Laboratory EA4662, University of \\ Franche-Comte, Besancon, France
}

\#These authors contributed equally to this work.

Correspondence to: Dr. Franck Grillet, MD. Department of Radiology, Centre Hospitalier Universitaire de Besancon, Boulevard Fleming, 25030 Besancon Cedex, France. Email: f1grillet@chu-besancon.fr.

Background: Increased prevalence of acute pulmonary embolism in COVID-19 has been reported in few recent studies. Some works have highlighted pathological changes on lung microvasculature with local pulmonary intravascular coagulopathy that may explain pulmonary artery thrombosis found on pulmonary computed tomography (CT) angiography. The objective of our study was to describe lung perfusion disorders assessed by pulmonary dual-energy CT (DECT) angiography in severe COVID-19 patients.

Methods: This single center retrospective study included 85 consecutive patients with a reverse transcriptase-polymerase chain reaction diagnosis of SARS-CoV-2 who underwent a pulmonary DECT angiography between March $16^{\text {th }} 2020$ and April 22 ${ }^{\text {th }}$ 2020. Pulmonary DECT angiography was performed when the patient had severe clinical symptoms or suffered from active neoplasia or immunosuppression. Two chest radiologists performed pulmonary angiography analysis in search of pulmonary artery thrombosis and a blinded semi quantitative analysis of iodine color maps focusing on the presence of parenchymal ischemia. The lung parenchyma was divided into volumes based on HU values. DECT analysis included lung segmentation, total lungs volume and distribution of lung perfusion assessment.

Results: Twenty-nine patients (34\%) were diagnosed with pulmonary artery thrombosis, mainly segmental (83\%). Semi-quantitative analysis revealed parenchymal ischemia in $68 \%$ patients of the overall population, with no significant difference regarding absence or presence of pulmonary artery thrombosis (23 vs. $35, \mathrm{P}=0.144)$. Inter-reader agreement of parenchymal ischemia between reader 1 and 2 was substantial [0.74; interquartile range (IQR): 0.59-0.89]. Volume of ischemia was significantly higher in patients with pulmonary artery thrombosis [29 (IQR, 8-100) vs. 8 (IQR, 0-45) $\left.\mathrm{cm}^{3}, \mathrm{P}=0.041\right]$. Lung parenchyma was divided between normal parenchyma (59\%, of which 34\% was hypoperfused), ground glass opacities (10\%, of which $20 \%$ was hypoperfused) and consolidation (31\%, of which $10 \%$ was hypoperfused).

Conclusions: Pulmonary perfusion evaluated by iodine concentration maps shows extreme heterogeneity in COVID-19 patients and lower iodine levels in normal parenchyma. Pulmonary ischemic areas were more frequent and larger in patients with pulmonary artery thrombosis. Pulmonary DECT angiography revealed a significant number of pulmonary ischemic areas even in the absence of visible pulmonary arterial thrombosis. This may reflect microthrombosis associated with COVID-19 pneumonia.

Keywords: COVID-19; lung diseases; computed tomography (CT); dual energy; computed tomography angiography; pulmonary embolism; pulmonary artery thrombosis

Submitted May 28, 2020. Accepted for publication Jun 19, 2020.

doi: 10.21037/qims-20-708

View this article at: http://dx.doi.org/10.21037/qims-20-708 


\section{Introduction}

Since the outbreak declared by the World Health Organization (WHO) in January 2020 caused by a new coronavirus, the Severe Acute Respiratory Syndrome Coronavirus 2 (SARS-CoV-2), responsible for the coronavirus disease named COVID-19, understanding its pathophysiological mechanism is challenging in order to explain its high mortality rate (1-3) .

The severity of COVID-19 is partly explained by the involvement of the pulmonary parenchyma, responsible for a pneumonia sometimes leading to an acute respiratory distress that can cause death. However, other mechanisms associated with the alveolar viral damage appear to play a key role in the progression and severity of the disease. One of the main assumptions is the association of COVID-19 with a severe systemic inflammatory reaction and vasculopathy which is responsible for endothelial lesions, coagulopathy and significantly increased thromboembolic events (4-9). This recently described COVID-19 chestpredominant vasculopathy (10), mainly affecting small vessels, was suggested to be named "novel pulmonary specific vasculopathy" by Fogarty et al. (4) or "microvascular COVID-19 lung vessels obstructive thromboinflammatory syndrome" by Ciceri et al. (8) as distinct to disseminated intravascular coagulopathy frequently found in systemic infections. Several studies reported major coagulation disorders, mostly found in mild and severe COVID-19 patients. Elevated plasma levels of fibrinogen degradation products, as an inflammatory marker, and D-dimers constitute independent risk biomarker of disease severity with poor prognosis $(3,11-14)$.

Chest imaging plays a central role in the diagnosis and evaluation of the severity of lung parenchyma involvement in patients with severe grade infection (15-17). Common chest computed tomography (CT) pattern of COVID-19 pneumonia as well as its outcome are now well known (18-23). While unenhanced chest CT has earned a key role in the assessment of COVID-19 pneumonia severity (3,24-30), very few studies have searched for these vascular abnormalities and pulmonary embolic events. First statements on pulmonary vascular changes have been reported on unenhanced chest CT scan, seemingly thickening and vascular enlargement (30) mostly in subsegmental vessels (31-33). Increased prevalence of acute pulmonary embolism in COVID-19 has been reported in few recent studies, estimated between $20.6 \%$ and $40 \%$ $(12,34,35)$. Moreover, pulmonary embolism appears to be a severity marker $(12,34,36,37)$. Interestingly, in all studies these pulmonary embolisms are mostly subsegmental $(34,37)$. In parallel, hematological and post-mortem studies have highlighted pathological changes on lung microvasculature with pulmonary microvascular thrombosis associated with the common diffuse alveolar damage observed in acute respiratory distress $(4,8,38-41)$. These data suggest that this local pulmonary intravascular coagulopathy may explain the pulmonary artery thrombosis found on pulmonary CT angiography. Yet, those vascular changes on small subsegmental vessels and microvascular thrombosis may be underestimated by pulmonary CT angiography.

We hypothesize that pulmonary dual-energy CT (DECT) angiography could provide valuable information on these vascular abnormalities in COVID-19 patients by evaluating lung perfusion disorders in addition to chest CT pattern. The objective of our study was thus to describe lung perfusion disorders assessed by pulmonary DECT angiography in severe COVID-19 patients.

\section{Methods}

\section{Study type and inclusion criteria}

The inclusion criteria were consecutive adult patients $(\geq 18$ years old) with a reverse transcriptase-polymerase chain reaction (RT-PCR) diagnosis (NucleoSpin ${ }^{\circledR}$ RNA Virus kit, Macherey-Nagel Inc., Bethlehem, PA, USA) of SARS-CoV-2 who underwent a pulmonary DECT angiography scan between March $16^{\text {th }} 2020$ and April $22^{\text {th }}$ 2020. Pulmonary DECT angiography was performed when clinical signs of severe grade infection were present (oxygen saturation below $92 \%$, polypnea over 25 cycles per minute, fever over $40{ }^{\circ} \mathrm{C}$, increasing oxygen needs), need for invasive mechanical ventilation, or when the patient suffered from comorbidities of active neoplasia, immunosuppression, history of organ or bone-marrow transplantation.

Exclusion criteria were: (I) patients with unenhanced chest CT scans; (II) patients with monoenergetic pulmonary CT angiography; (III) patients with artifacts on pulmonary DECT angiography hindering image quality.

\section{Study population}

A flowchart of the study population is shown in Figure 1. Eighty-five patients were included and underwent further analysis. Demographics and clinico-biological data were gathered from medical charts. The following data were 


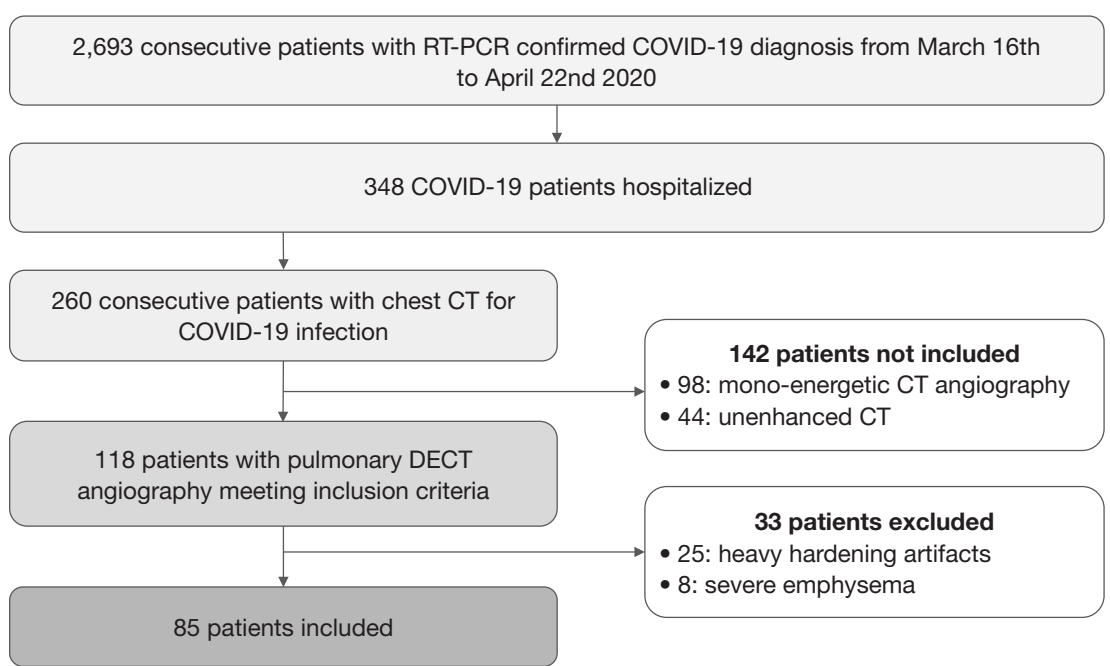

Figure 1 Flow chart of the study population. COVID-19, coronavirus disease-19. RT-PCR, reverse transcriptase-polymerase chain reaction; DECT, dual energy computed tomography.

reported: (I) information concerning COVID-19 (onset of symptoms, delay between first symptoms and pulmonary DECT angiography realization, RT-PCR results), (II) care status of the patient at pulmonary DECT realization (ambulatory care, conventional care unit, critical care unit), (III) need for invasive mechanical ventilation at the time of the DECT or in the following 12 hours after the pulmonary DECT angiography.

\section{Pulmonary DECT angiography protocol}

CT scans were acquired in helical dual-energy mode with a single-source rapid kilovolt switching CT scanner (Revolution, GE Healthcare, Milwaukee, WI, USA) after intravenous injection of $70 \mathrm{~mL}$ iodinated contrast agent (Iomeprol $400 \mathrm{mg} \mathrm{I} / \mathrm{mL}$, Bracco Imaging, Milan, IT, USA) at a flow rate of $4 \mathrm{~mL} / \mathrm{s}$, triggered on the main pulmonary artery. CT scan settings were set with tube voltage between 80 and $140 \mathrm{kV}$ every 0.5 milliseconds, $128 \times 0.625 \mathrm{~mm}$ (total collimation width $80 \mathrm{~mm}$ ), rotation time $0.8 \mathrm{~s}$, dose modulation (reference level of $280 \mathrm{~mA}$ ), pitch 0.992 and CTDIvol 13.6 mGy.

\section{Imaging analysis}

Imaging results were first reviewed by two chest radiologists (J Behr and A Busse-Coté with respectively 11 and 2 years of experience in chest imaging) on a PACS workstation (Carestream Health, Rochester, NY, USA). Readers were blinded to the patient's status, clinical and biological features. They were asked to assess the presence or absence of acute pulmonary artery thrombosis, defined as a filling defect within pulmonary vessels. When present, readers were asked to report the extent of emboli: unilateral or bilateral, number of lung lobes involved, and its topography: proximal, lobar and segmental or subsegmental. In case of discordance between readers, a simultaneous reading to reach consensus was achieved.

Pulmonary DECT angiography semi quantitative analysis was done on a dedicated spectral imaging post-processing software (Thoracic VCAR with GSI pulmonary perfusion, Advantage Workstation platform, Version 3.2 Ext 3.3, GE Healthcare, Milwaukee, WI, USA). Initial post-treatment was lung segmentation, excluding small pulmonary vessels and airways. A semi-quantitative analysis focusing on the presence of parenchymal ischemia was performed using iodine lung color maps. Readers were blinded to the presence or not of acute pulmonary artery thrombosis. They were asked to assess the presence of parenchymal ischemia, defined as subpleural wedge shaped or systematized hypoperfusion on iodine lung color maps (Figure 2). In case of discordance between readers, a simultaneous reading to reach consensus was achieved. When observed, the volume of parenchymal ischemia was segmented and measured (in $\mathrm{cm}^{3}$ and relative to total lungs volume in percent).

Quantitative analysis of segmented lung parenchyma led to total lungs volume $\left(\mathrm{cm}^{3}\right)$, average and standard deviation of iodine lungs concentration $\left(100 \mu \mathrm{g} / \mathrm{cm}^{3}\right)$ measurements. 

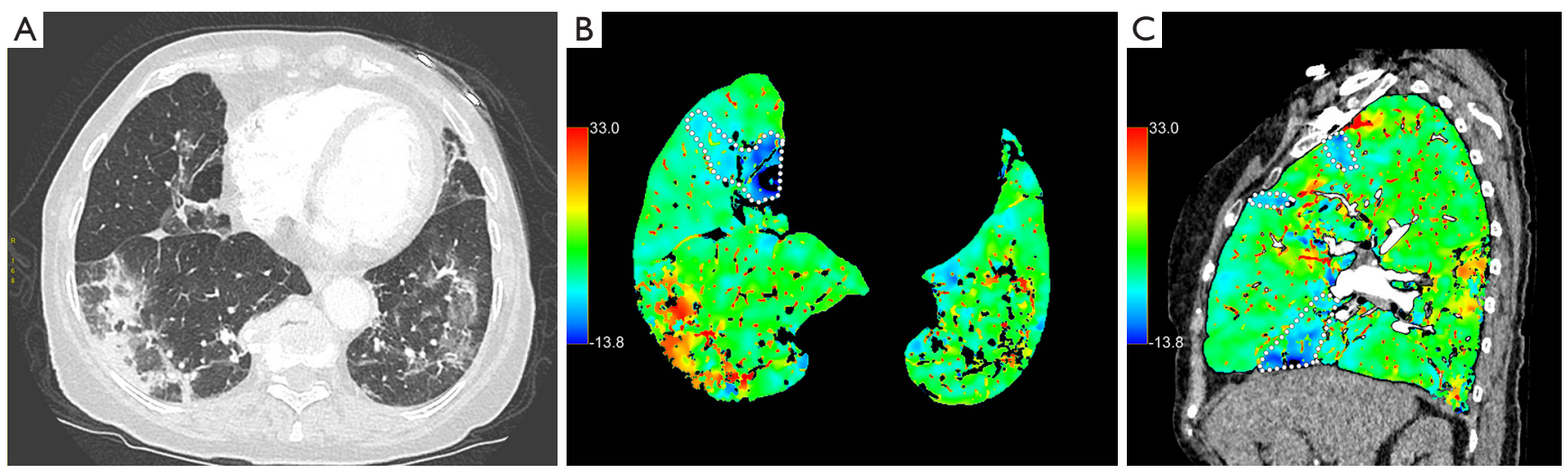

Figure 2 Pulmonary DECT angiography of a 57-year-old patient in critical care unit 6 days after the onset of COVID-19 symptoms. CT was performed because of progressive clinical state worsening. No acute pulmonary embolism was noted on CT pulmonary angiography in corresponding segmental arteries. Axial monoenergetic CT image (A, lung window): COVID-19 CT pattern associating a right inferior lobe consolidation and ground glass opacities in both inferior lobes. Axial iodine color map (B): segmental hypoperfused area in the middle lobe (dotted line). Right inferior lobe consolidation shows high and heterogeneous iodine levels. Iodine color overlay on sagittal CT image (C, mediastinal window): segmental and subsegmentals hypoperfused wedge-shaped areas consistent with pulmonary ischemia in right superior and middle lobes (inferior segment). DECT, dual energy computed tomography.

Total iodine lungs quantity $(100 \mu \mathrm{g})$ was defined as the product of total lungs volume and average of iodine lungs concentration. The lung parenchyma was divided into three volumes (absolutes and relatives to total lung volume) thanks to maps based on HU values as follows: normal $=(-1,024 \mathrm{HU} ;-730 \mathrm{HU})$, ground glass $=(-729 \mathrm{HU}$; $-647 \mathrm{HU})(42)$, and consolidation $=(-646 \mathrm{HU} ;+1,024 \mathrm{HU})$. In the absence of definition in the literature, another threshold was defined for dense consolidation $\geq 0 \mathrm{HU}$. The volume of relative perfusion deficit was measured, defined by an iodine concentration $<200 \mu \mathrm{g} / \mathrm{cm}^{3}(43,44)$. This volume may be impacted by contrast agent iodine volume, flow rate and timing of imaging. In order to describe the distribution of perfusion deficit area within the lungs, the relatively less perfused quartile lungs volume was segmented by adjusting the iodine concentration threshold so that the relative perfusion deficit volume was $25 \%$ of total lungs volume. This allowed to calculate the intersections between this hypoperfused quartile volume and the three sub-parts (normal, ground glass, consolidation) of the lung parenchyma, and in the end to assess the repartition (\%) of hypoperfused quartile volume between normal lung, ground glass and consolidation.

\section{Statistical analysis}

Quantitative data was expressed as mean \pm standard deviation (normally distributed data) or median and $25 \%$ and $75 \%$ interquartile ranges (IQR) (non-normal distribution parameter). Categorical variables were expressed as number (percentage). Continuous variables were compared between the two groups by using the Wilcoxon test (non-normal distribution verified by ShapiroWilk tests) a student test when distribution was normal. Qualitative variables were compared with Pearson $\chi^{2}$ or Fisher exact tests, as appropriate. Inter-reader agreement was analyzed using weighted kappa statistics for the presence of parenchymal ischemia at semi-quantitative analysis. A P value $<0.05$ was considered statistically significant. All analyses were performed with $\mathrm{R}$ version 3.4.4 (R Core Team 2017).

\section{Results}

\section{Study population}

The mean age of the patients was $65 \pm 13$ years old with a sex ratio of 1.83 ( $55 \mathrm{men} / 30$ women). Among the 85 patients, 8 $(9 \%)$ received ambulatory care, 47 (55\%) were hospitalized in a conventional care unit and $30(35 \%)$ were admitted to critical care unit. A total of 29 (34\%) patients required invasive mechanical ventilation. The characteristics of the study population are detailed in Table 1 .

Twenty-nine patients (34\%) were diagnosed with acute pulmonary artery thrombosis. Among these, 16 (55\%) were 
Table 1 Characteristics of the study population. Pulmonary dual energy CT angiography features according to the presence of pulmonary embolism

\begin{tabular}{|c|c|c|c|c|}
\hline Characteristics & Total $(\mathrm{n}=85)$ & $\begin{array}{l}\text { COVID-19 patients } \\
\text { without pulmonary } \\
\text { embolism } \\
(n=56,66 \%)\end{array}$ & $\begin{array}{l}\text { COVID-19 patients } \\
\text { with pulmonary } \\
\text { embolism } \\
(n=29,34 \%)\end{array}$ & $P$ value \\
\hline Age & $65 \pm 13$ & $65 \pm 14$ & $66 \pm 13$ & 0.698 \\
\hline \multicolumn{5}{|l|}{ Sex, n [\%] } \\
\hline Female & $30[35]$ & $20[36]$ & $10[34]$ & 0.910 \\
\hline \multicolumn{5}{|l|}{ Type of care, n [\%] } \\
\hline Ambulatory & $8[9]$ & $6[11]$ & $2[7]$ & \\
\hline Conventional care & $47[55]$ & 35 [63] & $12[41]$ & 0.001 \\
\hline Total lungs volume $\left(\mathrm{cm}^{3}\right)$ & $3,108[2,458-4,049]$ & $3,169[2,534-4,156]$ & $2,795[2,189-3,935]$ & 0.264 \\
\hline \multicolumn{5}{|l|}{ Lung texture analysis } \\
\hline Normal parenchyma (volume, $\mathrm{cm}^{3}$ ) & $1,902[807-2,649]$ & $1,998[1,173-3,011]$ & $1,581[645-2,419]$ & 0.092 \\
\hline Normal parenchyma (relative volume, \%) & 59 [40-72] & $62[47-77]$ & 55 [32-65] & 0.027 \\
\hline Ground glass opacity (volume, $\mathrm{cm}^{3}$ ) & 301 [224-397] & $301[227-388]$ & 308 [224-423] & 0.785 \\
\hline Ground glass opacity (relative volume, \%) & $10[7-14]$ & $10[7-13]$ & $12[7-17]$ & 0.219 \\
\hline Consolidation (volume, $\mathrm{cm}^{3}$ ) & $816[585-1,106]$ & $709[534-1,090]$ & $954[767-1,160]$ & 0.037 \\
\hline Consolidation (relative volume, \%) & $31[18-43]$ & 26 [17-39] & 36 [24-57] & 0.029 \\
\hline Relative ischemia volume (relative volume, \%) & $0.5[0-3]$ & $0[0.3-1.3]$ & $1[0-3]$ & 0.025 \\
\hline \multicolumn{5}{|l|}{ Quantitative dual-energy CT features } \\
\hline Total iodine lungs quantity $(100 \mu \mathrm{g})$ & $\begin{array}{c}27,135 \\
{[21,968-32,769]}\end{array}$ & $\begin{array}{c}25,997 \\
{[21,657-31,449]}\end{array}$ & $\begin{array}{c}29,507 \\
{[22,961-35,048]}\end{array}$ & 0.264 \\
\hline Standard deviation of iodine lungs concentration $\left(100 \mu \mathrm{g} / \mathrm{cm}^{3}\right)$ & $14.5[13.15-16.6]$ & $12.8[14.0-15.7]$ & $15.4[14.2-17.9]$ & 0.280 \\
\hline Relative perfusion deficit (volume, $\mathrm{cm}^{3}$ ) & $652[391-1,069]$ & $678[410-1,169]$ & 636 [372-945] & 0.402 \\
\hline Relative perfusion deficit (relative volume, \%) & $22[14-31]$ & 22 [14-33] & 23 [15-31] & 0.707 \\
\hline Normal lung within hypoperfused quartile lungs (\%) & 20 [17-22] & $20[11-30]$ & $21[13-32]$ & 0.216 \\
\hline Ground glass opacity within hypoperfused quartile lungs (\%) & $2[1-2]$ & $2[1-2]$ & $2[1-2]$ & 0.467 \\
\hline Consolidation within hypoperfused quartile lungs (\%) & $3[2-5]$ & $3[2-5]$ & $5[2-6]$ & 0.249 \\
\hline
\end{tabular}



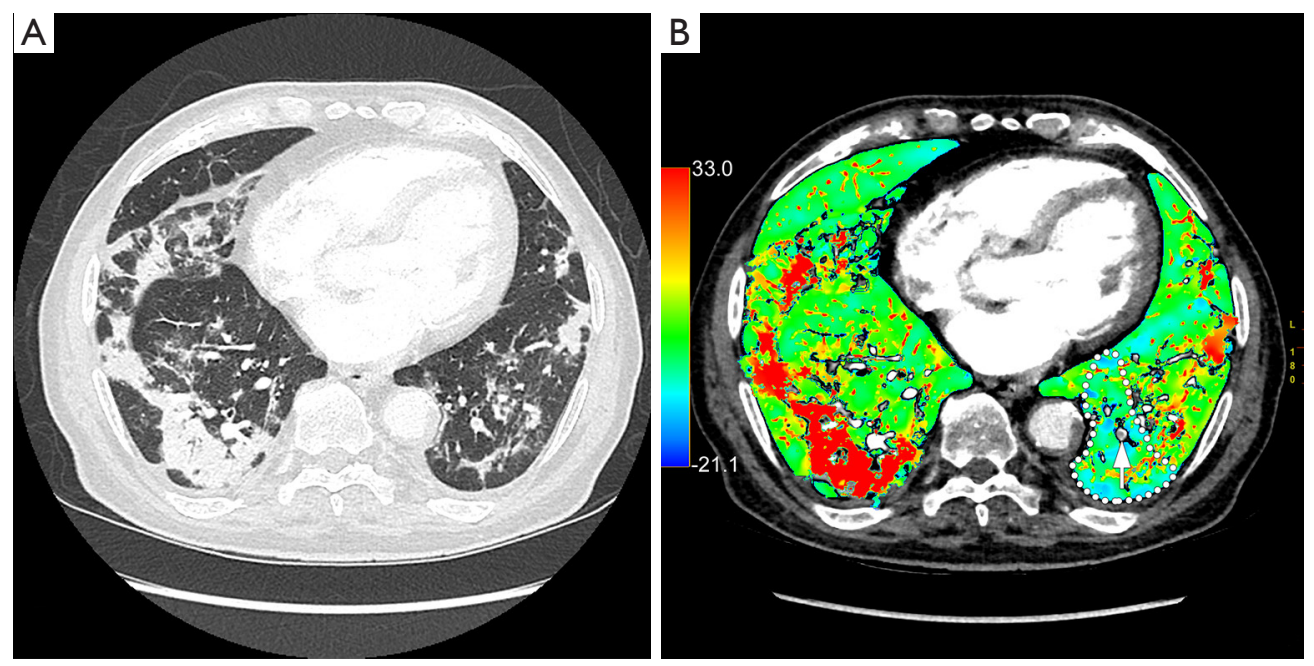

Figure 3 Pulmonary DECT angiography of an 84-year-old patient performed 14 days after COVID-19 symptoms onset because of clinical state worsening necessitating transfer to critical care unit. Axial monoenergetic CT image (A, lung window): COVID-19 CT pattern associating central ground glass opacities and peripheral declive areas of consolidation. Iodine color overlay on axial CT image (B, mediastinal window): heterogeneity of iodine map with high iodine concentrations in consolidations, and left medio-basal segment hypoperfusion (dotted line), secondary to the thrombosis of corresponding segmental pulmonary artery (white arrow). DECT, dual energy computed tomography.

bilateral; 24 (83\%) were segmental or subsegmental, 1 was lobar $(3 \%)$ and $4(14 \%)$ were mixed. None was proximal. The mean age was not statistically different in the patients with or without pulmonary artery thrombosis $(65 \pm 14$ and $66 \pm 13$ respectively, $\mathrm{P}=0.698$ ).

\section{Semi-quantitative DECT analysis}

As portrayed in Table 1, parenchymal ischemia was described in 58 patients $(68 \%)$, in both groups, with no significant difference between patients with and without pulmonary artery thrombosis (Figures 2,3) (35 vs. 23, $\mathrm{P}=0.144$ ). Interreader agreement of parenchymal ischemia between readers 1 and 2 was substantial (0.74; IQR: 0.59-0.89). Volume of ischemia was however significantly higher in patients with acute pulmonary artery thrombosis $[29$ (IQR, 8-100) vs. 8 (IQR, 0-45) $\left.\mathrm{cm}^{3}, \mathrm{P}=0.041\right]$. Other semi quantitative DECT analysis' results are detailed in Table 1.

\section{Quantitative lung analysis}

Quantitative lung analysis' characteristics are detailed in Table 1. Patients with acute pulmonary artery thrombosis had significantly less normal parenchyma (55\%; IQR, $32-65 \%$ ) than patients with no acute pulmonary artery thrombosis (62\%; IQR, 47-77\%), $\mathrm{P}=0.027)$. Patients with acute pulmonary artery thrombosis also had significantly more consolidations [36\% (IQR, 24-57\%) vs. 26\% (IQR, $17-39 \%$ ), $\mathrm{P}=0.029]$ and dense consolidations [ $8 \%$ (IQR, $3-14 \%$ ) vs. 4\% (IQR, 1-6\%), $\mathrm{P}=0.025$, respectively].

\section{Quantitative DECT analysis}

Total iodine lungs quantity, standard deviation of iodine lungs concentration, relative perfusion deficit and the repartition (\%) of hypoperfused quartile volume between normal lung, ground glass and consolidation are presented in Table 1. The hypoperfused areas were predominantly located within normal lung (Figure 4), and ground glass opacities and consolidations appeared mostly hyperperfused (Figure 5).

\section{Discussion}

To our knowledge, lung perfusion disorders have not yet been analysed by pulmonary DECT angiography in COVID-19 patient. Hypoperfused areas consistent with ischemia were searched for and quantified, with readers blinded for the diagnosis of acute pulmonary artery thrombosis. Although pulmonary ischemic areas were more 


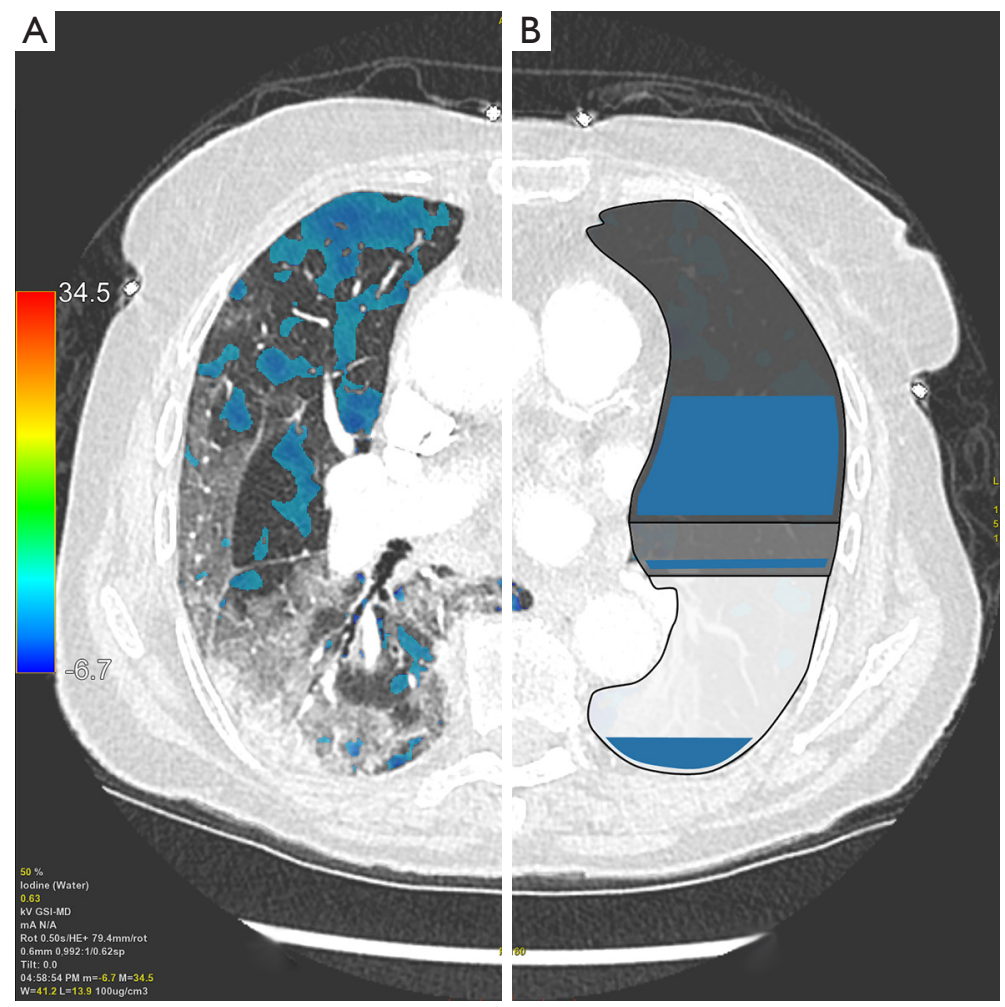

Figure 4 Pulmonary DECT angiography of an 89-year-old female without acute pulmonary embolism. The CT scan was obtained 2 days after the onset of COVID-19 symptoms and on the day the patient was transferred to the conventional care unit. Right lung (A) is an axial monoenergetic CT image (lung window) with overlay of the relatively hypoperfused quartile: perfusion deficit areas are mostly within normal parenchyma, and covers few areas of ground glass opacities and consolidations. Left lung (B) is a schematic representation, in the whole population, of the distribution of relatively hypoperfused quartile of the lungs (blue) within normal parenchyma (dark grey, 59\%, of which $34 \%$ is hypoperfused), ground glass opacities (light grey, $10 \%$, of which $20 \%$ is hypoperfused) and consolidation (white, $31 \%$, of which $10 \%$ is hypoperfused).

frequent and larger in the pulmonary artery thrombosis subgroup, interestingly we found a significant number of them in the absence of pulmonary artery thrombosis subgroup, mainly distal and of smaller volume. Recently, publications $(4,8,35,40,41)$ have reported microvascular lesions especially endothelial lesions and pulmonary vessels microthrombosis associated with COVID-19 and seem to be related to fatal outcome and death (41). We hypothesize that the small pulmonary ischemic areas that we detected on pulmonary DECT angiography with no visible pulmonary artery thrombosis could be the imaging consequence of these microvascular lesions and "in-situ" microthrombosis in opposition to real pulmonary artery thrombosis coming from the periphery. As suggested by Thachil et al. (10) it would be appropriated to refer to "pulmonary in-situ thrombosis" in COVID-19 rather than the denomination "pulmonary embolism". This distinction is not only semantical, as thrombosis treatment would rely not only on anticoagulant therapy but on antiplatelet agents in addition with anticoagulant (10). Beyond the illustration of a physiopathological mechanism of COVID-19, further studies will be necessary to look for an association of perfusion features with patients' outcome under treatment.

Lung perfusion analysis in these patients is challenging. Indeed, iodine maps in COVID-19 patients show extreme heterogeneity: areas of highly perfused consolidations, areas of ground glass opacities with normal or high perfusion and hypoperfused normally ventilated lung parenchyma. We hypothesize that high iodine levels in consolidations could be linked with the inflammatory nature of these consolidations. A higher density threshold helps to reduce the amount of non-consolidated lung mistakenly included 

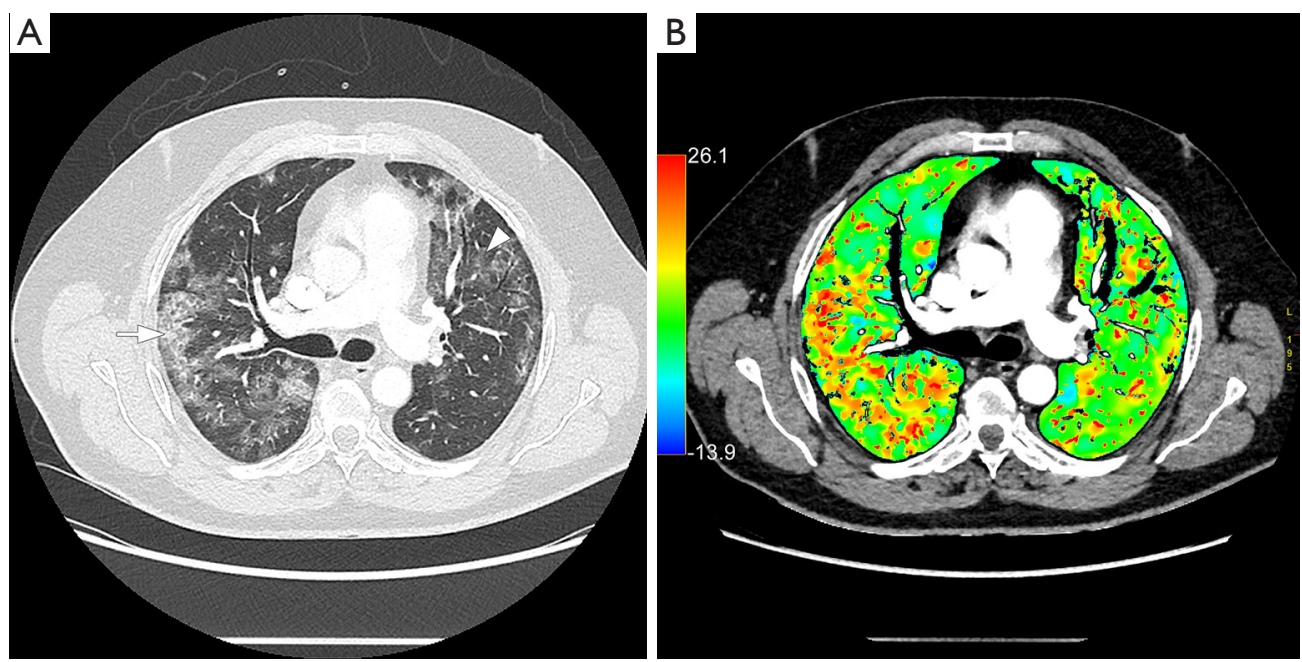

Figure 5 Pulmonary DECT angiography of a 55-year-old patient in ambulatory care, sent to the emergency room by his general practitioner 8 days after COVID-19 symptoms onset. Patient was hypoxemic with a $\mathrm{PaO}_{2} / \mathrm{FiO}_{2}$ ratio of 278 . Axial monoenergetic CT image (A, lung window): COVID-19 CT pattern with peripheral ground glass opacities (arrowhead) associated with areas of consolidation (arrow) in declive lung areas. Its extent is mild (45\% of whole lung volume). Iodine color overlay on axial CT image (B, mediastinal window): iodine map shows relatively hyperperfused consolidations and ground glass opacities especially in the right inferior lobe. Iodine map is heterogeneous even in the absence of segmental hypoperfusion (ischemia). DECT, dual energy computed tomography.

in a continuous lung segmentation based on density, especially when considering dense, incompletely ventilated, lung parenchyma.

We acknowledge some limitations of this study. First its retrospective monocentric design could lead to a selection bias. We limited this bias by including consecutive patients. Secondly, we excluded patients $(21 \%)$ when DECT quality was too low due to technics inherent artifacts (overweight, beam hardening artifacts). This relatively high rate of exclusion is explained by the accumulation of these artifacts in COVID-19 critical care patients. A reading bias related to any semi-quantitative analysis also exists, which has been minimized by double-blind reading with secondary consensus. Finally, iodine concentration is strongly correlated to lung parenchyma blood perfusion and can be impacted by contrast media variables as well as patient's heart flow and blood volume.

\section{Conclusions}

Pulmonary perfusion evaluated by iodine concentration maps shows extreme heterogeneity in COVID-19 patients and lower iodine levels in normal parenchyma. Pulmonary ischemic areas were more frequent and larger in patients with pulmonary artery thrombosis. Pulmonary DECT angiography revealed a significant number of pulmonary ischemic areas even in the absence of visible pulmonary arterial thrombosis. This may reflect microthrombosis associated with COVID-19 pneumonia.

\section{Acknowledgments}

Funding: None.

\section{Footnote}

Conflicts of Interest: All authors have completed the ICMJE uniform disclosure form (available at http://dx.doi. org/10.21037/qims-20-708). The authors have no conflicts of interest to declare.

Ethical Statement: In the context of the COVID-19 pandemic, our national commission for the protection of personal data considered that, for single-centre observational research associated with COVID-19, the need for information of patients and families was waived. Our study protocol followed the ethical guidelines of the Helsinki declaration (as revised in 2013) and was approved 
by our institutional review board.

Open Access Statement: This is an Open Access article distributed in accordance with the Creative Commons Attribution-NonCommercial-NoDerivs 4.0 International License (CC BY-NC-ND 4.0), which permits the noncommercial replication and distribution of the article with the strict proviso that no changes or edits are made and the original work is properly cited (including links to both the formal publication through the relevant DOI and the license). See: https://creativecommons.org/licenses/by-nc-nd/4.0/.

\section{References}

1. Müller O, Neuhann F, Razum O. Epidemiologie und Kontrollmaßnahmen bei COVID-19. Dtsch Med Wochenschr 2020;145:670-4.

2. Cheng Z, Lu Y, Cao Q, Qin L, Pan Z, Yan F, Yang W. Clinical Features and Chest CT Manifestations of Coronavirus Disease 2019 (COVID-19) in a SingleCenter Study in Shanghai, China. AJR Am J Roentgenol 2020;215:121-6.

3. Huang C, Wang Y, Li X, Ren L, Zhao J, Hu Y, Zhang L, Fan G, Xu J, Gu X, Cheng Z, Yu T, Xia J, Wei Y, Wu W, Xie X, Yin W, Li H, Liu M, Xiao Y, Gao H, Guo L, Xie J, Wang G, Jiang R, Gao Z, Jin Q, Wang J, Cao B. Clinical features of patients infected with 2019 novel coronavirus in Wuhan, China. Lancet 202;395:497-506.

4. Fogarty H, Townsend L, Ni Cheallaigh C, Bergin C, Martin-Loeches I, Browne P, Bacon CL, Gaule R, Gillett A, Byrne M, Ryan K, O'Connell N, O'Sullivan JM, Conlon N, O'Donnell JS. COVID19 coagulopathy in Caucasian patients. Br J Haematol 2020;189:1044-9.

5. Tang N, Li D, Wang X, Sun Z. Abnormal coagulation parameters are associated with poor prognosis in patients with novel coronavirus pneumonia. J Thromb Haemost 2020;18:844-7.

6. Violi F, Pastori D, Cangemi R, Pignatelli P, Loffredo L. Hypercoagulation and Antithrombotic Treatment in Coronavirus 2019: A New Challenge. Thromb Haemost 2020;120:949-56.

7. Oudkerk M, Büller HR, Kuijpers D, van Es N, Oudkerk SF, McLoud TC, Gommers D, van Dissel J, Ten Cate H, van Beek EJ. Diagnosis, Prevention, and Treatment of Thromboembolic Complications in COVID-19: Report of the National Institute for Public Health of the Netherlands. Radiology 2020. [Epub ahead of print]. doi: 10.1148/radiol.2020201629.
8. Ciceri F, Beretta L, Scandroglio AM, Colombo S, Landoni G, Ruggeri A, Peccatori J, D'Angelo A, De Cobelli F, Rovere-Querini P, Tresoldi M, Dagna L, Zangrillo A. Microvascular COVID-19 lung vessels obstructive thromboinflammatory syndrome (MicroCLOTS): an atypical acute respiratory distress syndrome working hypothesis. Crit Care Resusc 2020;22:95-7.

9. Tal S, Spectre G, Kornowski R, Perl L. Venous Thromboembolism Complicated with COVID-19: What Do We Know So Far? Acta Haematol 2020. [Epub ahead of print]. doi: 10.1159/000508233.

10. Thachil J, Srivastava A. SARS-2 Coronavirus-Associated Hemostatic Lung Abnormality in COVID-19: Is It Pulmonary Thrombosis or Pulmonary Embolism? Semin Thromb Hemost 2020. [Epub ahead of print]. doi: 10.1055/s-0040-1712155.

11. Zhou F, Yu T, Du R, Fan G, Liu Y, Liu Z, Xiang J, Wang Y, Song B, Gu X, Guan L, Wei Y, Li H, Wu X, Xu J, Tu S, Zhang Y, Chen H, Cao B. Clinical course and risk factors for mortality of adult inpatients with COVID-19 in Wuhan, China: a retrospective cohort study. Lancet 2020;395:1054-62.

12. Leonard-Lorant I, Delabranche X, Severac F, Helms J, Pauzet C, Collange O, Schneider F, Labani A, Bilbault P, Moliere S, Leyendecker P, Roy C, Ohana M. Acute Pulmonary Embolism in COVID-19 Patients on CT Angiography and Relationship to D-Dimer Levels. Radiology 2020. [Epub ahead of print]. doi: 10.1148/ radiol.2020201561.

13. Gao Y, Li T, Han M, Li X, Wu D, Xu Y, Zhu Y, Liu Y, Wang X, Wang L. Diagnostic utility of clinical laboratory data determinations for patients with the severe COVID-19. J Med Virol 2020;92:791-6.

14. Zou Y, Guo H, Zhang Y, Zhang Z, Liu Y, Wang J, Lu H, Qian $Z$. Analysis of coagulation parameters in patients with COVID-19 in Shanghai, China. Biosci Trends 2020. [Epub ahead of print]. doi: 10.5582/bst.2020.03086.

15. Rubin GD, Ryerson CJ, Haramati LB, Sverzellati N, Kanne JP, Raoof S, Schluger NW, Volpi A, Yim JJ, Martin IBK, Anderson DJ, Kong C, Altes T, Bush A, Desai SR, Goldin O, Goo JM, Humbert M, Inoue Y, Kauczor HU, Luo F, Mazzone PJ, Prokop M, Remy-Jardin M, Richeldi L, Schaefer-Prokop CM, Tomiyama N, Wells AU, Leung AN. The Role of Chest Imaging in Patient Management during the COVID-19 Pandemic: A Multinational Consensus Statement from the Fleischner Society. Radiology 2020;296:172-80.

16. ACR Recommendations for the use of Chest Radiography 
and Computed Tomography (CT) for Suspected COVID-19 Infection [Internet]. 2020. Available online: https://www.acr.org/Advocacy-and-Economics/ACRPosition-Statements/Recommendations-for-ChestRadiography-and-CT-for-Suspected-COVID19-Infection

17. Schiaffino S, Tritella S, Cozzi A, Carriero S, Blandi L, Ferraris L, Sardanelli F. Diagnostic Performance of Chest $\mathrm{X}$-Ray for COVID-19 Pneumonia During the SARSCoV-2 Pandemic in Lombardy, Italy. J Thorac Imaging 2020;35:W105-6.

18. Chung M, Bernheim A, Mei X, Zhang N, Huang M, Zeng X, Cui J, Xu W, Yang Y, Fayad ZA, Jacobi A, Li K, Li S, Shan H. CT Imaging Features of 2019 Novel Coronavirus (2019-nCoV). Radiology 2020;295:202-7.

19. Simpson S, Kay FU, Abbara S, Bhalla S, Chung JH, Chung M, Henry TS, Kanne JP, Kligerman S, Ko JP, Litt H. Radiological Society of North America Expert Consensus Statement on Reporting Chest CT Findings Related to COVID-19. Endorsed by the Society of Thoracic Radiology, the American College of Radiology, and RSNA. J Thorac Imaging 2020;35:219-27.

20. Revel MP, Parkar AP, Prosch H, Silva M, Sverzellati N, Gleeson F, Brady A; European Society of Radiology (ESR) and the European Society of Thoracic Imaging (ESTI). COVID-19 patients and the radiology department - advice from the European Society of Radiology (ESR) and the European Society of Thoracic Imaging (ESTI). Eur Radiol 2020. [Epub ahead of print]. doi: 10.1007/s00330-02006865-y.

21. Salehi S, Abedi A, Balakrishnan S, Gholamrezanezhad A. Coronavirus Disease 2019 (COVID-19): A Systematic Review of Imaging Findings in 919 Patients. AJR Am J Roentgenol 2020;215:87-93.

22. Zhou S, Zhu T, Wang Y, Xia L. Imaging features and evolution on CT in 100 COVID-19 pneumonia patients in Wuhan, China. Eur Radiol 2020. [Epub ahead of print]. doi: 10.1007/s00330-020-06879-6.

23. Xiong Y, Sun D, Liu Y, Fan Y, Zhao L, Li X, Zhu W. Clinical and High-Resolution CT Features of the COVID-19 Infection: Comparison of the Initial and Follow-up Changes. Invest Radiol 2020;55:332-9.

24. Wu J, Wu X, Zeng W, Guo D, Fang Z, Chen L, Huang H, Li C. Chest CT Findings in Patients with Coronavirus Disease 2019 and Its Relationship With Clinical Features. Invest Radiol 2020;5 5:257-61.

25. Pan F, Ye T, Sun P, Gui S, Liang B, Li L, Zheng D, Wang J, Hesketh RL, Yang L, Zheng C. Time Course of Lung Changes at Chest CT during Recovery from Coronavirus
Disease 2019 (COVID-19). Radiology 2020;295:715-21.

26. Bernheim A, Mei X, Huang M, Yang Y, Fayad ZA, Zhang N, Diao K, Lin B, Zhu X, Li K, Li S, Shan H, Jacobi A, Chung M. Chest CT Findings in Coronavirus Disease-19 (COVID-19): Relationship to Duration of Infection. Radiology 2020;295:200463.

27. Huang L, Han R, Ai T, Yu P, Kang H, Tao Q, Xia L. Serial Quantitative Chest CT Assessment of COVID-19: DeepLearning Approach. Radiol Cardiothorac Imaging 2020. doi: 10.1148/ryct.2020200075.

28. Liang T, Liu Z, Wu CC, Jin C, Zhao H, Wang Y, Wang Z, Li F, Zhou J, Cai S, Liang Y, Zhou H, Wang X, Ren Z, Yang J. Evolution of CT findings in patients with mild COVID-19 pneumonia. Eur Radiol 2020. [Epub ahead of print]. doi: 10.1007/s00330-020-06823-8.

29. Yu Q, Wang Y, Huang S, Liu S, Zhou Z, Zhang S, Zhao Z, Yu Y, Yang Y, Ju S. Multicenter cohort study demonstrates more consolidation in upper lungs on initial CT increases the risk of adverse clinical outcome in COVID-19 patients. Theranostics 2020;10:5641-8.

30. Spagnolo $\mathrm{P}$, Cozzi A, Foà RA, Spinazzola A, Monfardini L, Bnà C, Alì M, Schiaffino S, Sardanelli F. CT-derived pulmonary vascular metrics and clinical outcome in COVID-19 patients. Quant Imaging Med Surg 2020;10:1325-33.

31. Qanadli SD, Beigelman-Aubry C, Rotzinger DC. Vascular Changes Detected With Thoracic CT in Coronavirus Disease (COVID-19) Might Be Significant Determinants for Accurate Diagnosis and Optimal Patient Management. AJR Am J Roentgenol 2020;215:W15.

32. Zhao W, Zhong Z, Xie X, Yu Q, Liu J. Relation Between Chest CT Findings and Clinical Conditions of Coronavirus Disease (COVID-19) Pneumonia: A Multicenter Study. AJR Am J Roentgenol 2020;214:1072-7.

33. Caruso D, Zerunian M, Polici M, Pucciarelli F, Polidori T, Rucci C, Guido G, Bracci B, de Dominicis C, Laghi A. Chest CT Features of COVID-19 in Rome, Italy. Radiology 2020;296:E79-85.

34. Grillet F, Behr J, Calame P, Aubry S, Delabrousse E. Acute Pulmonary Embolism Associated with COVID-19 Pneumonia Detected by Pulmonary CT Angiography. Radiology 2020. [Epub ahead of print]. doi: 10.1148/ radiol.2020201544.

35. Middeldorp S, Coppens M, van Haaps TF, Foppen M, Vlaar AP, Müller MCA, Bouman CCS, Beenen LFM, Kootte RS, Heijmans J, Smits LP, Bonta PI, van Es N. Incidence of venous thromboembolism in hospitalized 
patients with COVID-19. J Thromb Haemost 2020. [Epub ahead of print]. doi: 10.1111/jth.14888.

36. Poissy J, Goutay J, Caplan M, Parmentier E, Duburcq T, Lassalle F, Jeanpierre E, Rauch A, Labreuche J, Susen S; Lille ICU Haemostasis COVID-19 group. Pulmonary Embolism in COVID-19 Patients: Awareness of an Increased Prevalence. Circulation 2020;142:184-6.

37. Chen J, Wang X, Zhang S, Liu B, Wu X, Wang Y, Wang $X$, Yang M, Sun J, Xie Y. Findings of Acute Pulmonary Embolism in COVID-19 Patients. SSRN Electron J 2020. doi: $10.2139 /$ ssrn. 3548771 .

38. Varga Z, Flammer AJ, Steiger P, Haberecker M, Andermatt R, Zinkernagel AS, Mehra MR, Schuepbach RA, Ruschitzka F, Moch H. Endothelial cell infection and endotheliitis in COVID-19. Lancet 2020;395:1417-8.

39. Ding Y, Wang H, Shen H, Li Z, Geng J, Han H, Cai J, Li X, Kang W, Weng D, Lu Y, Wu D, He L, Yao K. The clinical pathology of severe acute respiratory syndrome (SARS): a report from China. J Pathol 2003;200:282-9.

40. Ackermann M, Verleden SE, Kuehnel M, Haverich A, Welte T, Laenger F, Vanstapel A, Werlein C, Stark H, Tzankov A, Li WW, Li VW, Mentzer SJ, Jonigk D.

Pulmonary Vascular Endothelialitis, Thrombosis, and

Cite this article as: Grillet F, Busse-Coté A, Calame P, Behr J, Delabrousse E, Aubry S. COVID-19 pneumonia: microvascular disease revealed on pulmonary dual-energy computed tomography angiography. Quant Imaging Med Surg 2020;10(9):1852-1862. doi: 10.21037/qims-20-708
Angiogenesis in Covid-19. N Engl J Med 2020;383:120-8. 41. Lax SF, Skok K, Zechner P, Kessler HH, Kaufmann N, Koelblinger C, Vander K, Bargfrieder U, Trauner M. Pulmonary Arterial Thrombosis in COVID-19 With Fatal Outcome: Results From a Prospective, Single-Center, Clinicopathologic Case Series. Ann Intern Med 2020. [Epub ahead of print]. doi: 10.7326/M20-2566.

42. Zhu Y, Tan Y, Hua Y, Zhang G, Zhang J. Automatic Segmentation of Ground-Glass Opacities in Lung CT Images by Using Markov Random Field-Based Algorithms. J Digit Imaging 2012;25:409-22.

43. Chae EJ, Seo JB, Jang YM, Krauss B, Lee CW, Lee HJ, Song KS. Dual-Energy CT for Assessment of the Severity of Acute Pulmonary Embolism: Pulmonary Perfusion Defect Score Compared with CT Angiographic Obstruction Score and Right Ventricular/Left Ventricular Diameter Ratio. AJR Am J Roentgenol 2010;194:604-10.

44. Zhang LJ, Zhou CS, Schoepf UJ, Sheng HX, Wu SY, Krazinski AW, Silverman JR, Meinel FG, Zhao YE, Zhang ZJ, Lu GM. Dual-energy CT lung ventilation/perfusion imaging for diagnosing pulmonary embolism. Eur Radiol 2013;23:2666-75. 